\title{
PROPRIEDADES TERMOFÍSICAS DE MISTURAS BINÁRIAS CONTENDO BIODIESEL E METANOL
}

\author{
T. M. B. U. MOREIRA ${ }^{1}$, A. J. SILVA ${ }^{1}$, B. S. $\operatorname{COSTA}^{2}$ e E. E. G. ROJAS ${ }^{1,2}$ \\ ${ }^{1}$ Universidade Federal Fluminense, Pós Graduação em Engenharia Mecânica \\ ${ }^{2}$ Universidade Federal Fluminense, Departamento de Engenharia de Agronegócios \\ E-mail para contato: edwin@vm.uff.br
}

\begin{abstract}
RESUMO - O biodiesel é um termo genérico que se refere a vários ácidos graxos mono-ésteres. É obtido a partir da conversão do triacilglicerídeo (óleos vegetais ou gorduras animais) através de vários processos de esterificação. Neste trabalho foram determinadas a viscosidade, massa específica e índice de refração de misturas binárias de biodiesel/metanol de 293,15 K até 313,15 K em diferentes concentrações. Os valores de viscosidade, densidade e índice de refração sofreram um decréscimo com o aumento da temperatura. Em relação à concentração, se observou uma relação indireta entre a concentração de metanol e as propriedades termofísicas. Os resultados obtidos foram correlacionados usando equações empíricas obtendo-se um bom ajuste entre os dados experimentais e os calculados. O conhecimento dessas propriedades termofísicas do biodiesel e suas misturas pode ser empregado no projeto de equipamentos e sistemas de tubulações industriais do biodiesel.
\end{abstract}

\section{INTRODUÇÃO}

O biodiesel é uma atraente fonte de energia renovável que pode ser usada em substituição ao diesel mineral ou adicionado a ele. O processo de produção de biodiesel mais utilizado é a transesterificação, onde os trigricerídeos de óleos vegetais ou gorduras animais reagem com um álcool e são convertidos em alquil-ésteres e glicerina. O metanol é o álcool mais usado na produção do biodiesel, no entanto, outros álcoois também podem ser usados para sua produção, como etanol, propanol, isobutanol e butanol (Verduzco, 2013 ; Moser, 2009).

Existem algumas vantagens do biodiesel em relação ao diesel, incluindo o fato de ser uma fonte de energia renovável, sua baixa inflamabilidade, o que o torna mais seguro em termos de transporte e armazenamento, sua inerente lubricidade e degradabilidade, além disso, é seguro para uso em todos os motores a diesel, sendo virtualmente livres de enxofre e aromáticos (Verduzco, 2013 ; Moser, 2009).

O conhecimento das propriedades termofísicas das substâncias e suas misturas é importante em termos de projeto de unidades de processo, bem como em termos da obtenção da especificação comercial das substâncias. A viscosidade e massa específica do biodiesel são propriedades de grande importância, pois são largamente usadas nos modelos de combustão e no projeto das operações de controle de processo e na determinação da qualidade do combustível. A massa específica é comumente usada em inúmeras operações unitárias para a produção do biodiesel, reatores, unidades de destilação, tanques de armazenamento e tubulações. A viscosidade é a propriedade física da substância que expressa sua resistência ao escoamento, é importante no 
projeto de equipamentos a serem usados na indústria, tais como tubulações e colunas de destilação (Verduzco, 2013, Moradi, 2013, Ustra, 2013).

O objetivo deste trabalho é determinar a viscosidade, massa específica e índice de refração de misturas biodiesel/metanol de 293,15K até 313,15K em diferentes concentrações de metanol.

\section{MATERIAIS E MÉTODOS}

Utilizou-se biodiesel (CESBRA química S/A, Brasil) e metanol espectroscópico (Vetec Química Fina, Brasil). As misturas de biodiesel e álcool foram preparadas em base molar, nas frações molares de biodiesel de 0,$2 ; 0,4 ; 0,6 ; 0,8$ e 1,0 utilizando-se uma balança analítica de precisão de $\pm 1 \cdot 10^{-3} \mathrm{~g}$. Avaliou-se a massa específica, índice de refração e viscosidade das misturas bem como do biodiesel puro nas temperaturas de 293,15, 298,15, 303,15, 308, 15 e 313,15K.

As amostras foram preparadas em três repetições e as propriedades apresentadas são resultado da média dos valores obtidos para cada amostra analisada. Os dados experimentais foram analisados utilizando o pacote Origin ${ }^{\circledR}$ 7.0.

A massa específica foi medida usando-se um densímetro de tubo vibratório (Anton Paar DMA4500M, Graz, Áustria) que possui precisão de $\pm 1,0 \cdot 10^{-5} \mathrm{~g} / \mathrm{cm}^{3}$, os índices de refração (n) das amostras foram medidos usando-se um refratômetro digital (Abbemat RXA170 Anton Paar, Graz, Áustria) acoplado ao densímetro digital com precisão de $\pm 4.0 \cdot 10^{-5}$. Tanto o densímetro como o refratômetro estavam acoplados a um carregador automático de amostras (Xsample 122 Anton Paar, Graz, Austria). A viscosidade foi medida usando-se o reômetro rotacional Thermo Haake MARS (Modular Advanced Rheometer System, Alemanha) utilizando-se geometria cone (C60/1 ${ }^{\circ} \mathrm{TiL}$ ) e placa (MPC 60). Os dados obtidos nos ensaios foram manipulados com o auxílio do software Haake RheoWin ${ }^{\circledR}$ Data Manager. (versão 4.41.0000).

\section{RESULTADOS E DISCUSSÃO}

\subsection{Massa Específica e Índice de Refração}

Os resultados experimentais de massa específica do biodiesel e suas misturas com metanol constam na Figura 1. Em uma dada temperatura, quanto maior a proporção de biodiesel na mistura biodiesel/etanol, maior a sua massa específica. À medida que se aumenta a temperatura a massa específica tanto do biodiesel como de suas misturas com o metanol diminui. Um comportamento similar foi encontrado para o índice de refração, para as mesmas condições de temperatura e composição da mistura, os resultados estão apresentados na Figura 2, Alkindi et al. (2008) concluíram em seus estudos que à medida que se adicionava etanol ao glicerol, que é um coproduto do processo de fabricação do biodiesel, tanto o índice de refração como a massa específica das misturas diminuíam, a mesma tendência observada para os resultados obtidos experimentalmente para as misturas biodiesel/metanol.

A massa específica e o índice de refração variaram linearmente com a temperatura (T) nas 
condições estudadas e podem ser estimados usando um modelo linear genérico apresentado na equação 1:

$$
\psi=A+B T
$$

onde $\psi$ é a propriedade termofísica e A e B são constantes obtidas a partir dos dados experimentais. A Tabela 1 contém os coeficientes obtidos a partir da regressão dos dados de massa específica e índice de refração. Os dados experimentais de massa específica e índice de refração puderam ser adequadamente representados pelo modelo linear proposto (equação 1) apresentando coeficientes de correlação $\left(\mathrm{R}^{2}\right)$ maiores do que 0,99 em todas as condições analisadas e os valores calculados a partir das equações encontram-se apresentados nas Figuras 1 e 2. Os resultados obtidos encontram-se em acordo com aqueles disponíveis na literatura, Ustra et al (2013), que analisaram a influência da temperatura na massa específica de ésteres metílicos e mel, respectivamente, também encontraram uma dependência linear da massa específica em relação à temperatura.

Tabela 1: Parâmetros ajustados para o modelo matemático polinomial (equação 1) para massa específica $(\rho)$ e índice de refração (n) de misturas biodiesel/metanol, onde w é dado em fração molar de biodiesel.

\begin{tabular}{|ccccccc|}
\hline \multicolumn{3}{c}{$\rho / \mathrm{kg} / \mathrm{m}^{3}$} \\
\hline $\mathrm{w}$ & $\mathrm{A}$ & $\mathrm{B}$ & $\mathrm{R}^{2}$ & $\mathrm{~A}$ & $\mathrm{~B}$ & $\mathrm{R}^{2}$ \\
\hline 1,0 & 1095,1619 & $-0,7253$ & 1,0000 & 1,576 & $-0,0004$ & 1,0000 \\
0,8 & 1096,7775 & $-0,7397$ & 1,0000 & 1,5733 & $-0,0004$ & 1,0000 \\
0,6 & 1096,8782 & $-0,7539$ & 1,0000 & 1,5684 & $-0,0004$ & 0,9999 \\
0,4 & 1095,6644 & $-0,7745$ & 1,0000 & 1,5575 & $-0,0004$ & 0,9994 \\
0,2 & 1091,6310 & $-0,8153$ & 1,0000 & 1,5406 & $-0,0004$ & 1,0000 \\
\hline
\end{tabular}




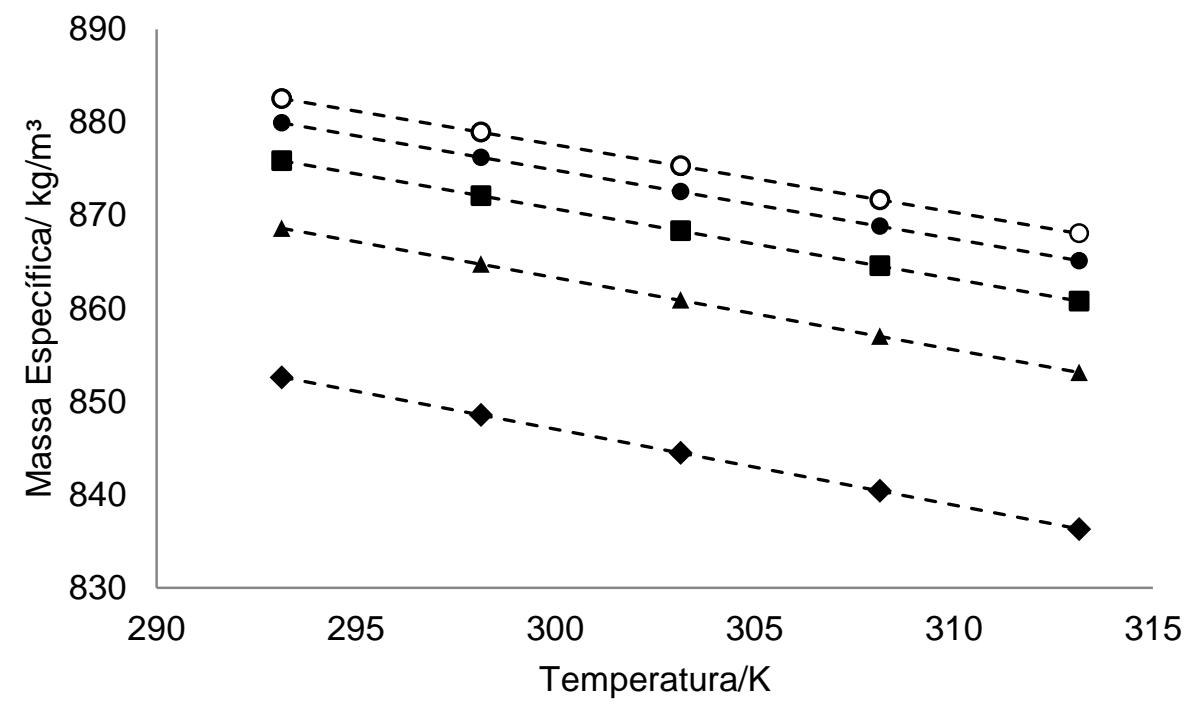

Figura 1: Variação da massa específica em função da temperatura. ( $~ 1,0 \bullet 0,8 \boldsymbol{\bullet} 0,6 \boldsymbol{\Delta} 0,4 \bullet 0,2$ em fração molar de biodiesel, -- curvas obtidas a partir dos dados calculados através da regressão linear).

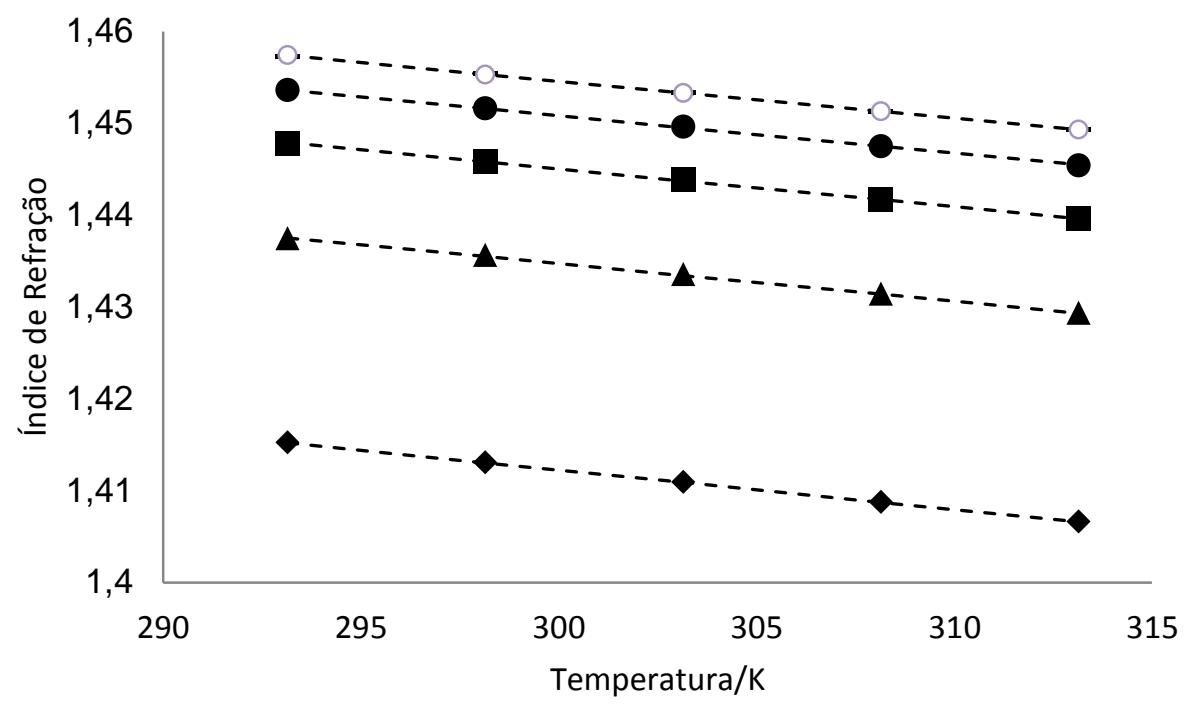

Figura 2: Variação do índice de refração em função da temperatura. ( $(\circ), 0 \bullet 0,8 \boldsymbol{\bullet} 0,6 \boldsymbol{\Delta} 0,4 \bullet 0,2$ em fração molar de biodiesel, -- curvas obtidas a partir dos dados calculados através da regressão linear). 


\subsection{Viscosidade}

A viscosidade das misturas binárias biodiesel/metanol diminui à medida que a mistura tornase mais concentrada em metanol e o aumento da temperatura também causa uma diminuição da viscosidade. Alkindi et al. (2008) verificaram que à medida de se adicionava etanol ao glicerol, a mistura tinha sua viscosidade diminuída, assim como ocorreu com a adição de metanol ao biodiesel. Em relação ao efeito do aumento da variação da viscosidade, Ustra et al.(2013) concluíram que o aumento da temperatura levava à uma diminuição da viscosidade de ésteres metílicos obtidos a partir do óleo de soja, mesmo efeito observado para o biodiesel e suas misturas com etanol analisadas. Os dados experimentais estão apresentados na Figura 3.

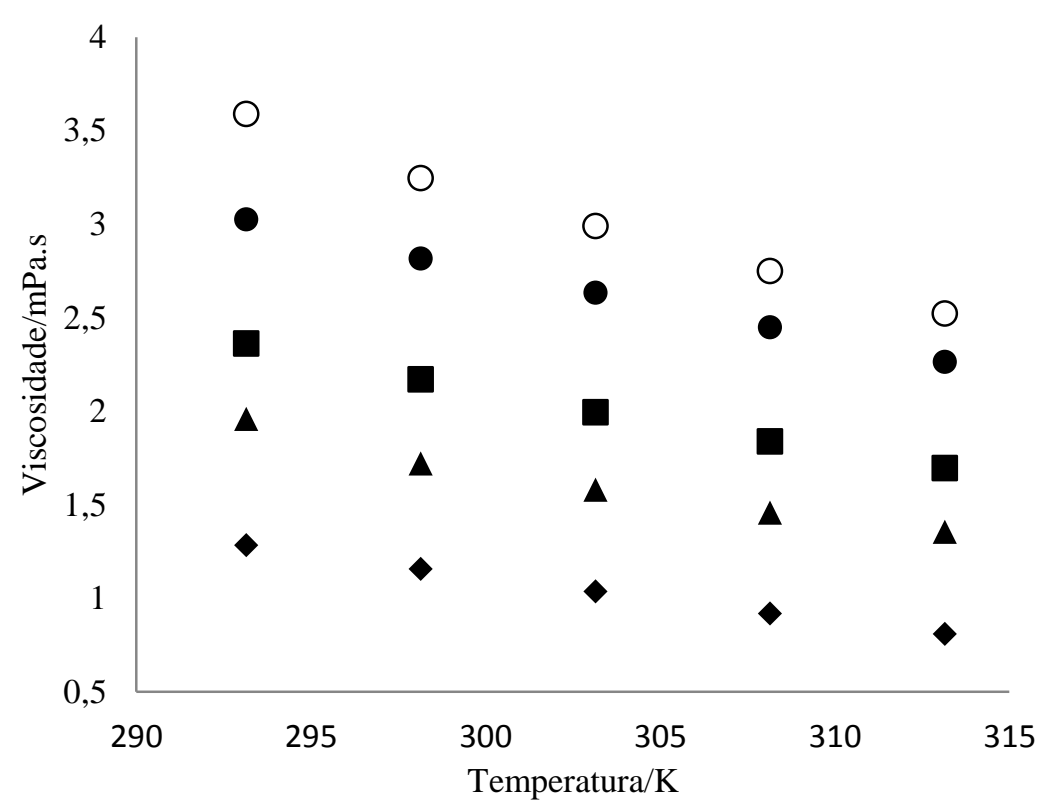

Figura 3: Variação da viscosidade em função da temperatura. ( ( $1,0 \bullet 0,8 \boldsymbol{\bullet} 0,6 \boldsymbol{\Delta} 0,4 \bullet 0,2 \mathrm{em}$ fração molar de biodiesel).

\subsection{Efeito Combinado da Temperatura e Concentração}

Costa et al. (2014) fizeram uso do modelo polinomial quadrático apresentado na equação 2 para descrever o comportamento de propriedades termofísicas de soluções aquosas de polietilenoglicol 1500 em função tanto da temperatura como em função da concentração do polietilenoglicol. Este mesmo modelo foi usado para descrever o comportamento das misturas analisadas em função da concentração de metanol e da temperatura.

$$
\psi=\beta_{0}+\beta_{1} w+\beta_{2} T+\beta_{3} w^{2}+\beta_{4} T^{2}+\beta_{5} w T
$$


Onde $\Psi$ é a propriedade física da mistura (massa específco, índice de refração ou viscosidade) $w$ é a fração molar de metanol, $T$ é a temperatura do sistema e os coeficientes $\beta_{0}, \beta_{l}$, $\beta_{2}, \beta_{3}, \beta_{4}, \beta_{5}$ são obtidos através de uma regressão não linear.

Estão apresentados na Tabela 2 os parâmetros obtidos com o ajuste dos dados experimentais ao modelo matemático proposto (equação 2). Os parâmetros não significativos foram eliminados com base em $\mathrm{p}>0,05$.

Tabela 2: Parâmetros ajustados para o modelo matemático polinomial (equação 2) para massa específica $(\rho)$, índice de refração $(n)$ e viscosidade $(\mu)$ de misturas biodiesel/metanol.

\begin{tabular}{cccccccc}
\hline$\psi$ & $\beta 0$ & $\beta 1$ & $\beta 2$ & $\beta 3$ & $\beta 4$ & $\beta 5$ & $\mathrm{R}^{2}$ \\
\hline$\rho / \mathrm{kg} / \mathrm{m}^{3}$ & - & 39,5117 & - & $-54,4976$ & - & - & 0,9922 \\
$\mu / \mathrm{mPa} .5$ & - & $-12,2737$ & $-0,3012$ & - & - & 0,0330 & 0,9935 \\
$\mathrm{n}$ & - & 0,0169 & - & $-0,0751$ & - & - & 0,9910 \\
\hline
\end{tabular}

Como os valores obtidos de coeficiente de correlação $\left(\mathrm{R}^{2}\right)$ estão muito próximos da unidade, pode-se dizer que o modelo matemático utilizado se ajustou adequadamente aos dados experimentais.

Diante dos resultados obtidos a partir do modelo utilizado, apresentados na Tabela 2. A massa específica $(\rho)$ e o índice de refração (n) apresentaram uma relação quadrática com a concentração de metanol e a influência da temperatura nessas propriedades foi desprezível em relação à influência exercida pela variação da concentração de metanol. A viscosidade apresentou uma dependência significativa tanto em relação à temperatura como em relação à concentração de metanol.

\section{CONCLUSÕES}

Os valores de viscosidade, densidade e índice de refração sofreram um decréscimo com o aumento da temperatura. Em relação à concentração, se observou uma relação indireta entre a concentração de metanol e as propriedades termofísicas. Os resultados obtidos foram correlacionados usando equações empíricas obtendo-se um bom ajuste entre os dados experimentais e os calculados. 


\section{REFERÊNCIAS}

ALKINDI, A. S., AL-WAHAIBI, Y. M., MUGGERIDGE, A. H. Physical properties (density, excess molar volume, viscosity, surface tension and refractive index) of ethanol + glycerol. $J$. Chem. Eng. Data. v. 53, p. 2793-2796, 2008.

COSTA, S. B., ROJAS, E. E. G., COIMBRA, J. S. R., TEIXEIRA, J. A., ROMERO, T. J. Density, refractive index, apparent specific volume, and electrical conductivity of aqueous solutions of poly(ethylene glycol) 1500 at different temperatures. J. Chem. Eng. Data. v. 59, p. 339-345, 2014.

MORADI, G. R., KARAMI, B., MOHADESHI, M. Densities and kinematic viscosities in biodiesel-diesel blends at various temperatures. J. Chem. Eng. Data. v. 58, p. 99-105, 2013.

MOSER, B. R. Biodiesel production, properties and feedstocks. In Vitro Cell. Dev, Biol. v. 45, p. 229-266, 2009.

USTRA, M. K., SILVA, J. R. F., ANSOLIN, M., BALEN, M., CANTELLI, K., ALKIMIM, I. P., MAZUTTI, M. A., VOLL, F. A. P., CABRAL, V. F., FILHO, C. L., CORAZZA, M. L., OLIVEIRA, J. V. Effect of temperature and composition in density, viscosity and thermal conductivity of fatty acid methyl esters from soybean, castor and Jatropha curcas oils. J. Chem. Eng. Data. v. 58, p. 460-466, 2013.

VERDUZCO, L. F. R. Density and viscosity of biodiesel as a function of temperature: Empirical models. Renew. and Sust. Energ. Rev. v. 19, p. 652-665, 2013. 